\title{
Simulation of the Indonesian land gravity data using a digital terrain model data
}

\author{
Leni Sophia Heliani ${ }^{1}$, Yoichi Fukuda ${ }^{2}$, and Shuzo Takemoto ${ }^{3}$ \\ Graduate School of Science, Kyoto University, Kitashirakawa, Oiwake-cho, Kyoto 606-8502, Japan
}

(Received March 11, 2003; Revised December 26, 2003; Accepted December 26, 2003)

\begin{abstract}
The Indonesian gravity field is neither accurately nor comprehensively determined, especially due to inadequacy of land gravity data. This study deals with determination of Indonesian land gravity and proposes the solution to data unavailability by means of a simulation technique. The simulation was carried out by combining short wavelength topographic effects from GTOPO30 and long wavelength information from EGM96. The simulated result was then compared with the observed gravity data. Over Java, Sumatra and Sulawesi islands, using three methods commonly used on the computation of topographic effect; topography, isostatic and RTM (Residual Terrain Model), it was estimated that error propagation by the GTOPO30 into the simulated gravity is about 4.5 to 11.7 mgal, with the RTM method was affected less than others. It was also shown that the simulated gravity from the RTM method gave the best agreement with STD (Standard Deviation) differences of 17 to $42 \mathrm{mgal}$ compared to the observed data. This result was achieved after applying optimal RTM parameters over the Indonesian area: a reference field of $25^{\prime}-27.5^{\prime}$ and density of $2-2.2 \mathrm{gr} / \mathrm{cm}^{3}$. Compared to STD differences between EGM96 and observed data, that between the simulated gravity and observed data improved by 2.5-7 mgal, and gave more detailed gravity features, especially over areas of high topography.
\end{abstract}

Key words: Gravity simulation, residual terrain model (RTM), topography, isostatic.

\section{Introduction}

Numerous gravity field studies required the knowledge of the gravity field without gaps. In general, however, gravity measurements are only possible at discrete points, with large gaps between them. The availability of satellite altimeterderived gravity data in the last two decades offers a solution to the problem of data unavailability over most ocean areas, although the accuracy is still low due to uncertainty in the sea surface topography and poor modelled tides. Over the land, although several new observations have been carried out recently, the restriction in the coverage of land data still remains. Some large areas of the Earth are not measured at all because of physical or technical limitations. Such conditions become a limiting factor on the determination of reliable gravity fields of the area of interest. Hence, interpolation within the gravity and estimation of unknown short wavelength components of the fields become necessary.

The Indonesian archipelago is located between longitudes of $95^{\circ} \mathrm{E}$ to $140^{\circ} \mathrm{E}$ and latitudes of $12^{\circ} \mathrm{S}$ to $10^{\circ} \mathrm{N}$ in the one of the most geodynamic areas of the world and where the Pacific and Indian Oceans meet. Thus, it plays an important role on the geodynamic and oceanographic studies. However, due to the scarcity of the gravity data, especially over land areas, the gravity field of the area has not been accurately and comprehensively determined. At present, the Indonesian gravity field is derived from INDGRID96, the gridded free-air anomalies obtained during the SE-Asia gravity project (SEAGP), joint project between Getech and Indone-

Copy right(c) The Society of Geomagnetism and Earth, Planetary and Space Sciences (SGEPSS); The Seismological Society of Japan; The Volcanological Society of Japan; The Geodetic Society of Japan; The Japanese Society for Planetary Sciences; TERRAPUB. sian Gravity Commision (KGN). However, its original data contain large data gaps especially over land areas of: Kalimatan, Sulawesi and Irian Jaya. The data gap was solved by interpolation the OSU91A global geopotential model (Kahar et al., 1997). Moreover, the history of INDGRID96 is not clear, thus it is difficult to estimate the accuracy of the obtained gravity field (Prijatna, 1998).

This paper discusses the derivation of the Indonesian land gravity map and the computation of simulated land gravity data as one solution to the unavalability of land gravity data. The simulation has been done by combining a short wavelength part of gravity obtained from computation of the gravity effect of topography using GTOPO30 data (USGS, 1996) and long wavelength information of gravity from EGM96 (Lemoine et al., 1997). The reliability of the simulation was estimated by comparison with the available observed land gravity data. Before simulating the land gravity, several tests and preliminary studies were done. First the GTOPO30 was validated to establish its accuracy in the study area. Further, three methods (e.g. Omang and Forsberg, 2000); topography, isostatic and RTM (residual terrain model), were assessed to estimate the influence of GTOPO30 error on the simulation process and to find out the most suitable method for the simulation gravity computation over the study area. For the RTM computation method, several reference systems and densities were tested to find the optimal RTM parameters over the Indonesian area. Lastly, to obtain more a reliable gravity field over the area, the simulated gravity was combined with observed gravity and the resulting data set was called "combined gravity". 

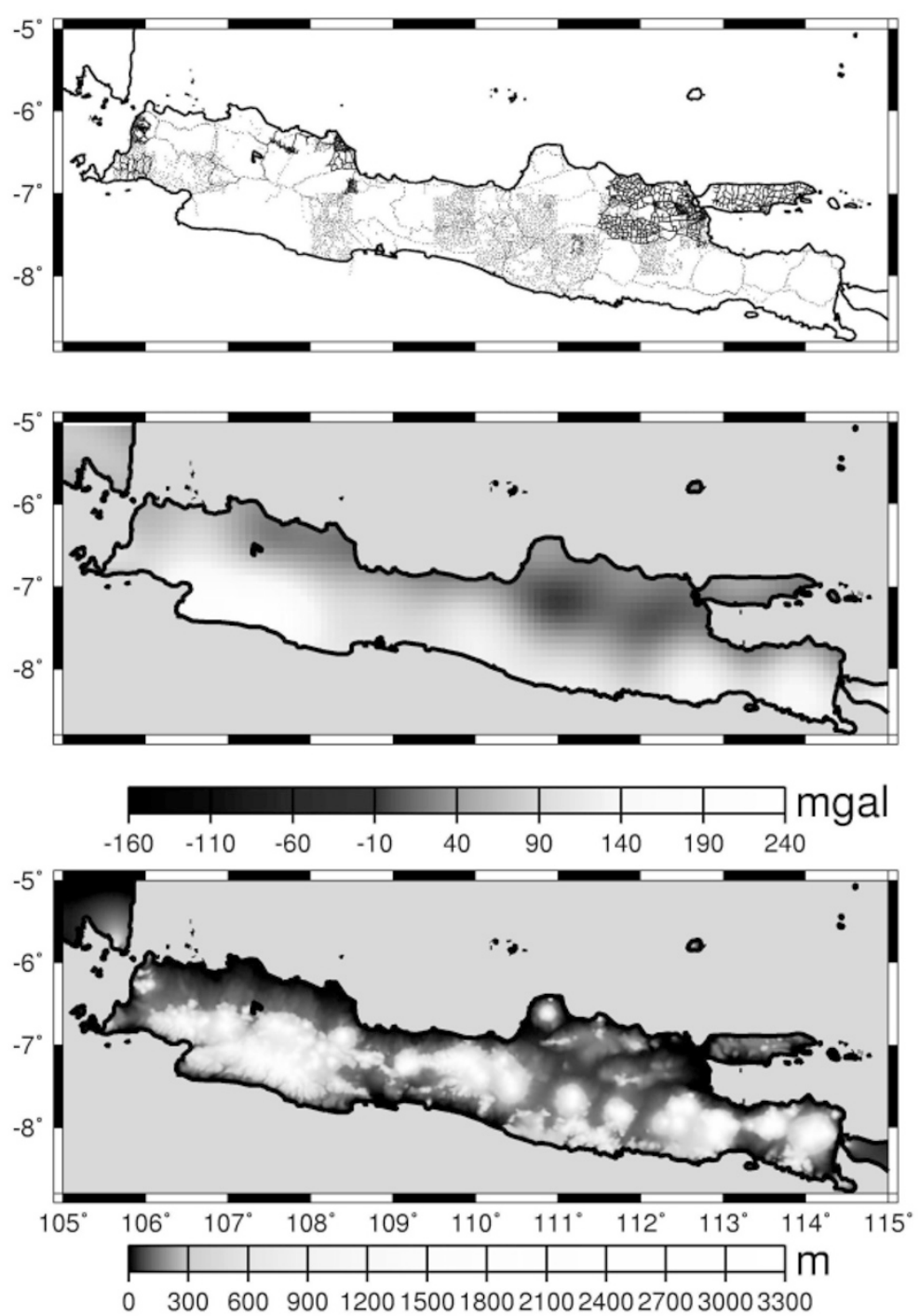

Fig. 1. The used data in this study over Java island: observed data distribution (above), EGM96 (middle) and GTOPO30 (bottom).

\section{Data}

In this study three kinds of data were used. First, 74208 co-located observed gravity and height data were used for comparison of gravity simulation results. These data are located over the three islands of Java, Sumatra and Sulawesi, where the coverage of observed data is relatively good and available for this study. In most cases, the data were observed after the 1960's. The heights were mainly established by means of conventional (spirit) leveling and barometricleveling (Getech, 1995), while the rest were interpolated from the stations height or topographic maps at scale of at least 1:250.000 (Kearsley and Ahmad, 1994). As for the gravity data, $45 \%$ in Java, $30 \%$ in Sumatra and all in Sulawesi are observed gravity data, while the remaining are Bouguer anomalies gravity interpolated from maps. The data were collected from several sources with purpose especially for geophysical explorations, and compiled during the SEAGP.

The next data are GTOPO30 and EGM96 for computation simulated gravity data. GTOPO30 is a global digital elevation model (DEM) with a horizontal grid spacing of 30 arc seconds (approximately $1 \mathrm{~km}$ ). The source of data over Java and Sumatra are from a digital chart of the world (DWC) developed by NIMA (Nation of Imagery and Mapping Agency) on the 1:1.000.000-scale Operational Navigation Chart (ONC) with the primary contour interval of 1000 $\mathrm{ft}(305 \mathrm{~m})$. On the other hand, the source of data over Sulawesi island is the Indonesian Army Map Services (AMS), which are paper maps at a scale of 1:1.000.000, digitized with the contour intervals of $100,150,300$, and $500 \mathrm{~m}$ (USGS, 1996). EGM96 is the most recent global geopotential model, with the data source of $30^{\prime} \times 30^{\prime}$ interval mean average gravity anomaly (Lemoine et al., 1997).

The absolute vertical accuracy of GTOPO30 varies by location according to the source data. The absolute vertical accuracy of the DCW, the vector source with the largest area of coverage, is stated in its product specification with RSME about $97 \mathrm{~m}$, while the AMS is stated with RMSE of $152 \mathrm{~m}$ (USGS, 1996). On the other hand, the accuracy of the observed height data was predicted to be less than $5 \mathrm{~m}$, as they were mainly observed by levelling and barometric-levelling (Getech, 1995). Compared to the GTOPO30 data, the observed height data still have better accuracy. Therefore, for the purpose of this study, it was used as control values in the 

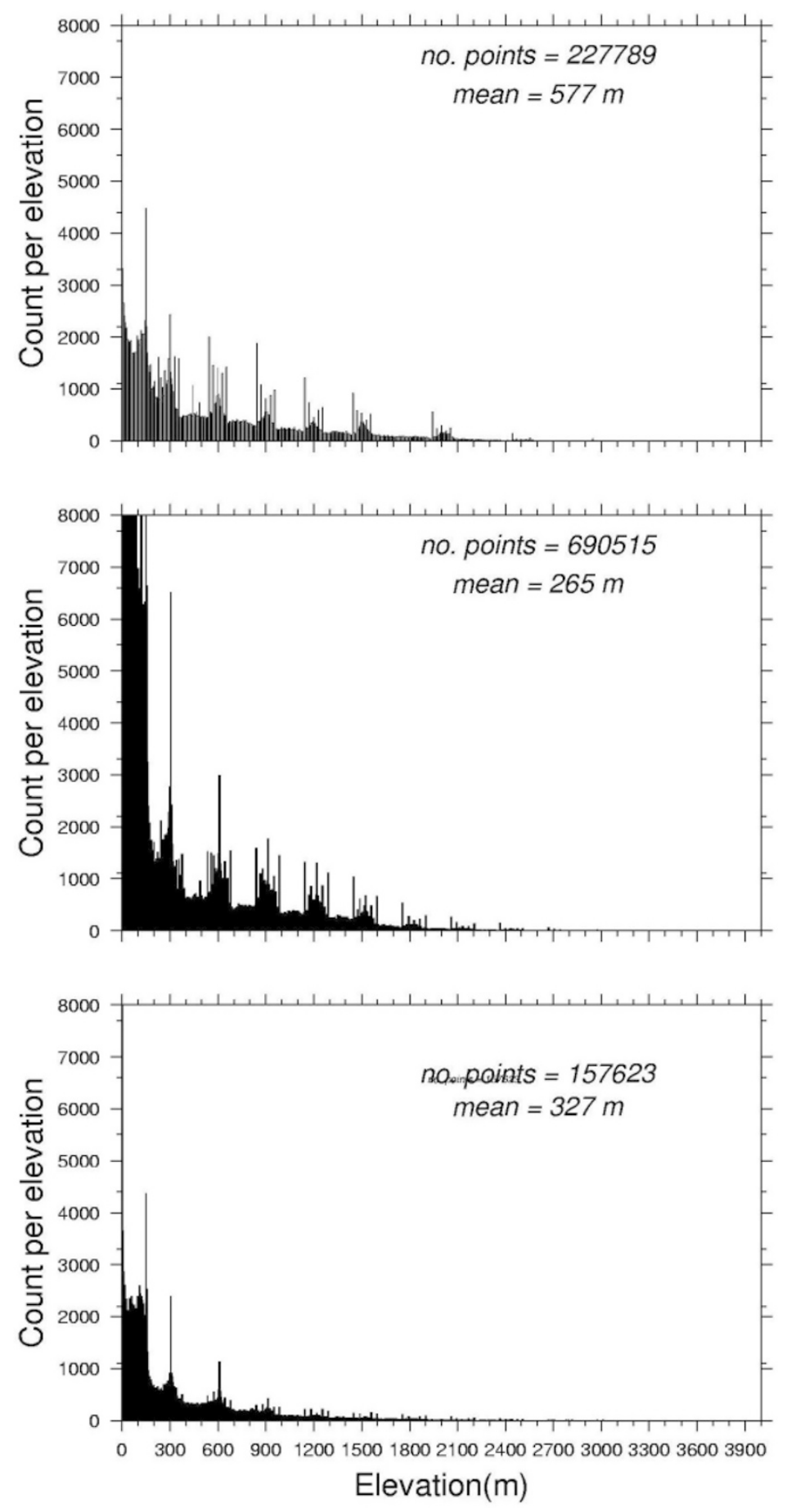

Fig. 2. Histogram of GTOPO30 over three islands: Java (bottom), Sumatra (middle) and Sulawesi (above).

GTOPO30 validation. Figure 1 shows the utilized data in this study over Java island: distribution of the observed data, EGM96 and GTOPO30.

\section{Validation of GTOPO30}

Two validation procedures were conducted: (1) histogrammic analysis of the GTOPO30 and the comparison to the observed data and, (2) statistical comparison with observed data on each island. For these purpose, the GTOPO30 data was interpolated on the area where the observed height data are available. The interpolation process was done using the "grdtrack" program from GMT (Wessel and Smith,
1991) utilizing the bicubic interpolation method. The differences between GTOPO30 and observed more than 3 times of STD were deleted. Finally the STD differences were computed from the remaining data.

The histogrammic analysis has been performed for two reasons: (1) to see if there is an error in the data and, (2) to understand the character of the data sources and the area. The histogram of the GTOPO30 data is shown in Fig. 2. In this, Java and Sumatra showed a similar pattern, as they are derived from the same source, with a past drop occurring before $200 \mathrm{~m}$ and then prominent sharp spikes and broader peaks at approximately $300 \mathrm{~m}$ increments. This suggests a 

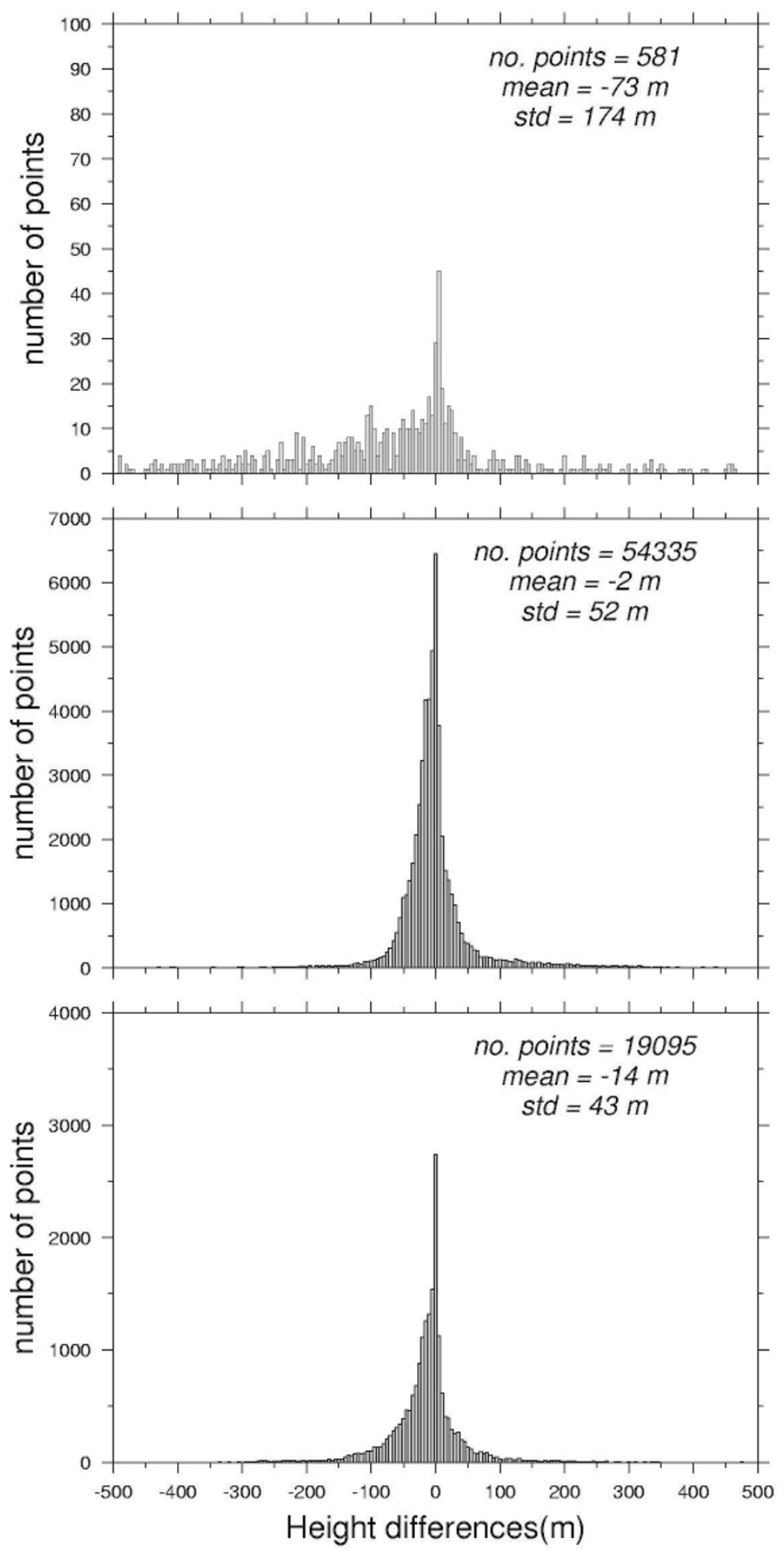

Fig. 3. Histogram of differences between GTOPO30 and observed height data: Java (bottom), Sumatra (middle) and Sulawesi (above).

contour interval of $300 \mathrm{~m}$ in the data source, with subsidiary contour interval at lower elevations less than 200 m. Meanwhile, the histogram of Sulawesi data shows prominent sharp spikes and broader peaks at approximately $300 \mathrm{~m}$ and $500 \mathrm{~m}$ increments. This suggests a combination of contour values of $300 \mathrm{~m}$ and $500 \mathrm{~m}$. These results are match to the contour interval used on deriving the GTOPO30 from its source data (USGS, 1996), as mentioned in Section 2.

The statistical comparison of GTOPO30 with the observed data over the three islands can be seen in Table 1 . In this case, the observed data is assumed to be true, as it was estimated having accuracy higher than GTOPO30 data. The results show that STD difference over Java island is less compared to the others, suggesting better agreement between GTOPO30 and observed data in general over the area. However, the mean values of Java and Sulawesi islands were not close to zero, indicating there are biases in GTOPO30. The possible reason is that the data source of the GTOPO30 is from small-scale maps, with greater contour interval in increasing in the height. In fact, most of the compared data 
Table 1. Statistics of differences between GTOPO30 and observed height data, unit in $\mathrm{m}$.

\begin{tabular}{cccccc}
\hline Island & No. data & Minimum & Maximum & Mean & STD \\
\hline Java & 19095 & -163.51 & 190.87 & -14.78 & 43.52 \\
Sumatra & 54335 & -294.38 & 299.98 & -2.60 & 52.81 \\
Sulawesi & 581 & -415.78 & 543.24 & -73.26 & 174.68 \\
\hline
\end{tabular}

\section{Topography}

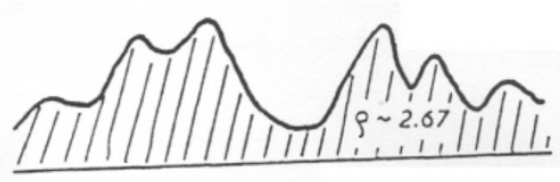

3. Residual terrain model

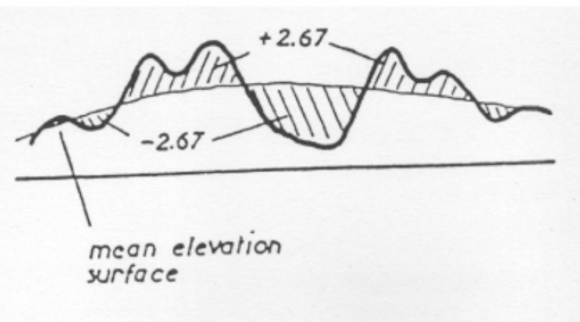

2. Isostatic

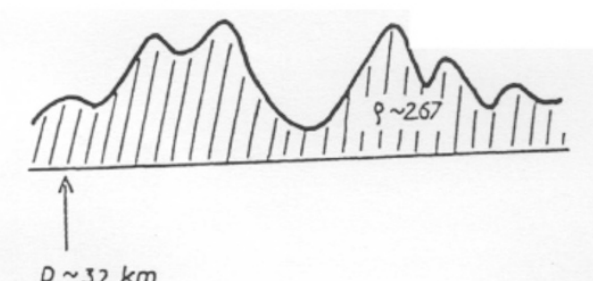

$D \sim 32 \mathrm{~km}$

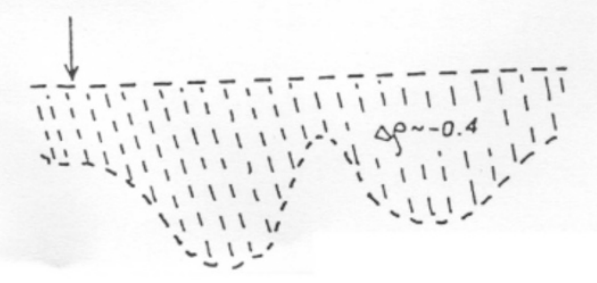

Fig. 4. Masses distribution on the computation methods of gravitational effect of topography: modified from Forsberg (1985).

over these islands are also located over high topographic areas. Accordingly, it is not surprising that a bias occurred in areas of such rough topographic variation. In contrast, over Sumatra Island, comparison points were mainly located over relatively lower topographic areas; the average height of the compared points over Sumatra is $96 \mathrm{~m}$, while in Java it is $140 \mathrm{~m}$. Thus bias is much less here. For further computation, the bias was subtracted and utilized the bias subtracted GTOPO30 data for further computation. To give a clear image of the comparison between observed and GTOPO30 data, the histogram of the differences between them was derived and is shown in Fig. 3. From the histogram, it can be seen that the distribution of the differences over Java and Sumatra islands are more normally distributed compared to the one over Sulawesi island, with the reason that it has being more accurate GTOPO30 data source, as mentioned in Section 2, and more homogeneous observed height data source, which mostly come from leveling and barometric-levelling data. On the other hand, the two peaks shown for the Sulawesi data due to its having the combination of two contour values and sparser contour interval corresponding with the increasing height in the GTOPO30 data source map, as mentioned above.

Both the histogram in Fig. 3 and the Table 1 show that the topography of GTOPO30 is generally lower than the observed data. Such a condition, from the contour differences map (not shown here), occurs especially over high topographic areas. Higher topographic values only occurs over the flat areas or close to the coastal areas. One of the reasons for that condition could be attributed partly to the GTOPO30 having less accuracy, especially over high topographic areas, as the contour interval is sparser from the height above 200 $\mathrm{m}$ on the digitizing source map.

\section{The gravitational Effect of Topography}

The gravitational effect of the topography data can be commonly determined using three methods (e.g. Omang and Forsberg, 2000): topography, isostatic, RTM. The distribution of density of each method can be seen in Fig. 4. The topography method considers the effect of Bouguer plate and terrain effect. In this case, Bouguer plate is assumed as the area around the gravity station which is completely flat and horizontal, with infinite radius, which may be regarded as a circular cylinder of thickness equal to $h$. Heiskanen and Moritz (1967) wrote the attraction of an infinite Bouguer plate as follows:

$$
A_{B}=2 \pi G \rho h .
$$

In this case, $h$ is height above sea level, $G$ is the constant gravitation and $\rho$ is the density. Further, the terrain effect refines the Bouguer plate attraction by taking into account the deviation of actual topography from the plate. This classical terrain correction given by an integral over the irregularities of the topographic mass body relative to a Bouguer plate passing through the computation point $p$ (Forsberg, 1985):

$$
C_{p}=G \rho \iint_{-\infty}^{\infty} \int_{z=h_{p}}^{z=h(x, y)}\left(\frac{z-h_{p}}{r^{3}}\right) d x d y d z
$$

where $r$ is the distance and $(x, y, z)$ is the point of integration with the height $z$. Topographical effect obtained from Topography method is: 
Table 2. Effect of GTOPO30 error on the computation of gravity effect of topography using topography, isostatic and RTM methods, unit in mgal.

\begin{tabular}{llcrrrr}
\hline Methods & Island & No. data & Minimum & Maximum & Mean & STD \\
\hline Topography & Java & 19095 & -28.60 & 47.70 & 1.30 & 6.01 \\
& Sumatra & 54335 & -211.7 & 67.11 & 0.50 & 9.70 \\
\multirow{2}{*}{ Isostatic } & Java & 19095 & -28.37 & 35.38 & 1.60 & 4.90 \\
& Sumatra & 54335 & -183.76 & -105.77 & 8.50 & 11.70 \\
RTM & Java & 19095 & -29.50 & 26.90 & -1.20 & 4.50 \\
& Sumatra & 54335 & -109.80 & 35.78 & 0.20 & 5.12 \\
\hline
\end{tabular}

Table 3. Summary of the comparison between simulated data computed by means of the three methods with the observed gravity, unit in mgal.

\begin{tabular}{llcrrrr}
\hline Methods & Island & No. data & Minimum & Maximum & Mean & STD \\
\hline Topography & Java & 19095 & -105.13 & 166.98 & 11.92 & 26.83 \\
& Sumatra & 54335 & -131.30 & 337.40 & 15.35 & 27.59 \\
\multirow{2}{*}{ Isostatic } & Java & 19095 & -107.00 & 116.67 & -1.49 & 21.23 \\
& Sumatra & 54335 & -133.30 & 272.75 & 0.70 & 21.53 \\
\multirow{2}{*}{ RTM } & Java & 19095 & -107.51 & 108.86 & -5.17 & 20.56 \\
& Sumatra & 54335 & -130.59 & 242.29 & 1.04 & 18.92 \\
\hline
\end{tabular}

$$
\Delta g_{T}=A_{B}+C_{p}
$$

The second of isostatic method, is not like topography method where the topographical masses are completely removed. In the isostatic, the masses are shifted into the interior of the reference field, in this case geoid, in order to make up the mass deficiencies that exist under the continent. Several isostatic models are available, and we chose the Airy-Heiskanen ( $\mathrm{AH}$ ) model, in which the topographic masses are used to fill the roots of the continent. The equilibrium for the continents can be formulated as (Heiskanen and Moritz, 1967)

$$
t \Delta \rho=h \rho .
$$

The compensation height (root) becomes:

$$
t=\frac{\rho}{\Delta \rho} h
$$

where $t$ is root depth, $\Delta \rho$ is density contrast between crust and upper mantle, $h$ is height of topography and $\rho$ is standard crust density of $2.67 \mathrm{~g} / \mathrm{cm}^{3}$. The normal thickness of the earth's crust is denoted by $D$ with a value of around $32 \mathrm{~km}$. The topographical effect computed by isostatic method is (e.g. Bajracharya et al., 2001):

$$
\Delta g_{\text {isostatic }}=A_{T}+A_{C} .
$$

where $A_{T}$ is effect of topographic masses above the geoid and $A_{C}$ is effect of the compensating masses based on the AH model. These two components of the isostatic topographical effect can be expressed as:

$$
A_{T}=G \rho \iint_{-\infty}^{\infty} \int_{0}^{h(x, y)}\left(\frac{z-h_{p}}{r^{3}}\right) d x d y d z
$$

$$
A_{C}=G \Delta \rho \int_{-\infty}^{\infty} \int_{-D-t-h(x, y)}^{-D-h(x, y)}\left(\frac{z-h_{p}}{r^{3}}\right) d x d y d z
$$

In the last of the RTM model method, the topographic data is divided into two parts: a smooth mean elevation surface and residual elevation surface. The smooth elevation is used to define a reference density model which has crustal density (e.g. $2.67 \mathrm{~g} / \mathrm{cm} 3$ ) up to the reference level. The reference surface can be defined corresponding to the global topography to a certain degree and order, but can as well be defined through a suitable filtering of the local terrain heights. The residual terrain is derived by subtracting the reference field from the local terrain. The RTM gravity effect of topography in the approximation is given by an integral of form (Forsberg, 1985) :

$$
\Delta g_{\mathrm{RTM}}=G \rho \iint_{-\infty}^{\infty} \int_{z=h_{\mathrm{ref}}(x, y)}^{z=h(x, y)}\left(\frac{z-h_{p}}{r^{3}}\right) d x d y d z
$$

The topographic RTM density anomalies will make a balance of positive and negative density anomalies, representing the area where the topography is either above or below the reference topography.

\section{Land Gravity Simulation}

The simulation process was done as follows:

$$
\Delta g_{\text {sim }}=\Delta g_{\mathrm{EGM} 96}+\Delta g_{\mathrm{TE}}
$$

where $\Delta g_{\text {sim }}$ is the simulated gravity anomaly, $\Delta g_{\text {EGM96 }}$ is the gravity anomaly from EGM96 and $\Delta g_{\mathrm{TE}}$ is the gravity effect of topography computed using the three methods mentioned above, further called terrain gravity. In this case, 
Table 4. Statistics of differences between simulated gravity using optimal RTM parameters and observed gravity data, unit in mgal.

\begin{tabular}{lrccrr}
\hline Island & No. data & Minimum & Maximum & Mean & STD \\
\hline Java & 19095 & -111.07 & 101.61 & -3.47 & 17.90 \\
Sumatra & 54335 & -130.01 & 186.96 & 3.90 & 16.67 \\
Sulawesi & 581 & -110.28 & 138.41 & -1.23 & 42.29 \\
\hline
\end{tabular}

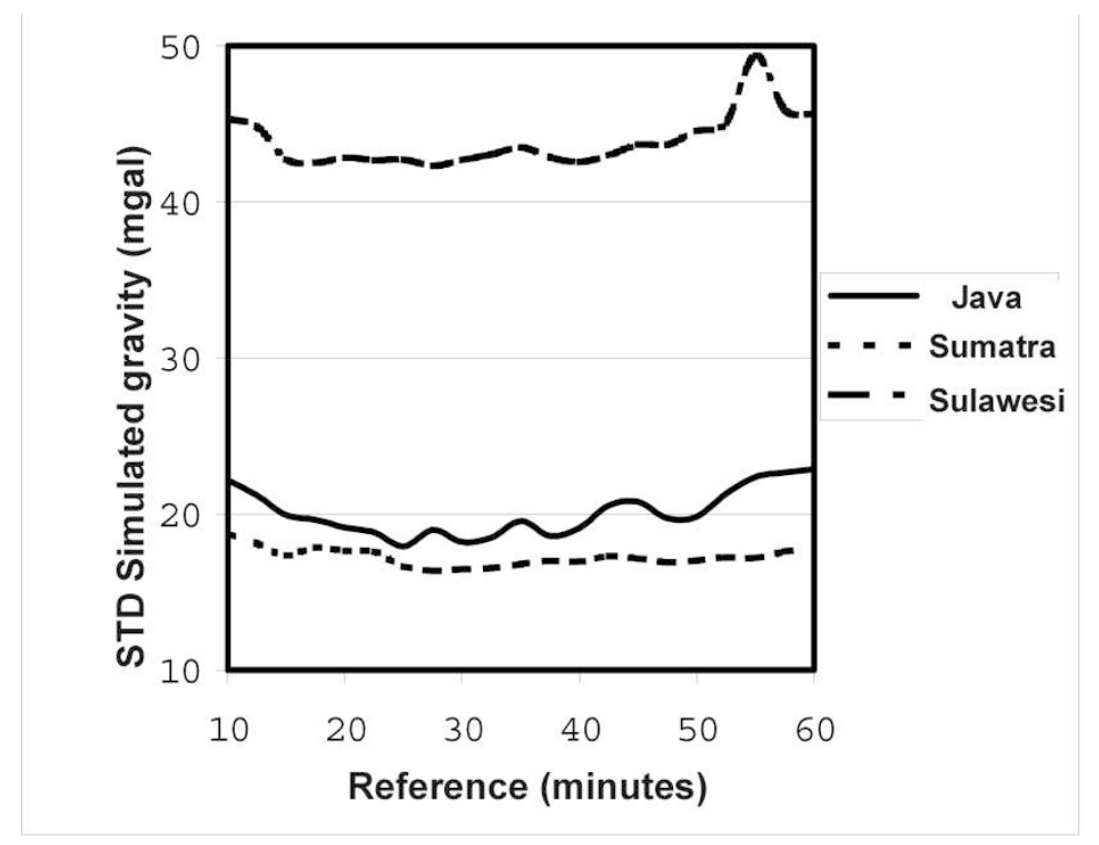

Fig. 5. Relationship between utilized reference field and simulated gravity.

the simulated gravity was obtained from the combination of EGM96 and terrain gravity. We know that the data source of the EGM96 is an average mean gravity of interval $30^{\prime} \times 30^{\prime}$ and represents a long-wavelength gravity signal. In contrast, GTOPO30 has an interval of $30^{\prime \prime} \times 30^{\prime \prime}$ and contains a shortwavelength gravity signal. Hence, the long-wavelength part of simulated gravity is obtained from the EGM96, whereas the short-wavelength part of it is defined from terrain gravity. And it hope that the information contained in GTOPO30 will give additional information to the EGM96 and yield a reasonable simulated gravity data.

\section{Results and Discussion}

\subsection{Effect of GTOPO30 error and utilized method on the computation of gravitational effect of topogra- phy}

There are two purposes of this section. The first is to estimate the effect of error content on GTOPO30 on various computation methods of gravitational effect of topography. Here, we expect to identify the method in which the GTOPO30 error causes minimum effect. The second purpose is to see or select the method which results in the most reasonable topography effect over the area. For the first purpose, topography, RTM, as well as isostatic method have been applied using GTOPO30 and observed height data over Java and Sumatra, where the amount and distribution of observed data are sufficient for this study. Further the corresponding differences between them were computed. The methods have been computed using the TC program from the GRAVSOFT package (Tscherning et al., 1992). For the RTM method, a commonly applied $30^{\prime} \times 30^{\prime}$ reference grid was first utilized by averaging the $30^{\prime \prime} \times 30^{\prime \prime}$ interval height of GTOPO30. The statistics of the differences (gravity effect of topography from GTOPO30 minus gravity effect of topography from observed data) are summarized in Table 2. From the results in Table 2, it seems that the GTOPO30 error has minimum effect on the RTM method, as shown by the smallest STD differences value among the three methods. This is understandable since the RTM method uses the averaged height data. Thus the results are less affected by the source height error.

Regarding the second purpose, the gravitational effect of topography obtained by the three methods above using GTOPO30 data was added by EGM96 data and the results were compared with the observed gravity data. The summary of the comparison results is shown in Table 3 . We can see that compared to the observed data, again the RTM method result shows the lowest STD differences among the three methods, suggesting that the RTM method yield a more reasonable results over the areas. The reason could be due to, as mentioned above, the topographic RTM density anomalies are balancing the positive and negative density anomalies in the represented area, where the topography is either above or below the reference topography. It is, therefore, closer to the actual topographic condition of the area than other methods. Accordingly, we utilized the RTM method on the simulation of land gravity data further. Mean value of the topography method is very large compared to others. The explana- 


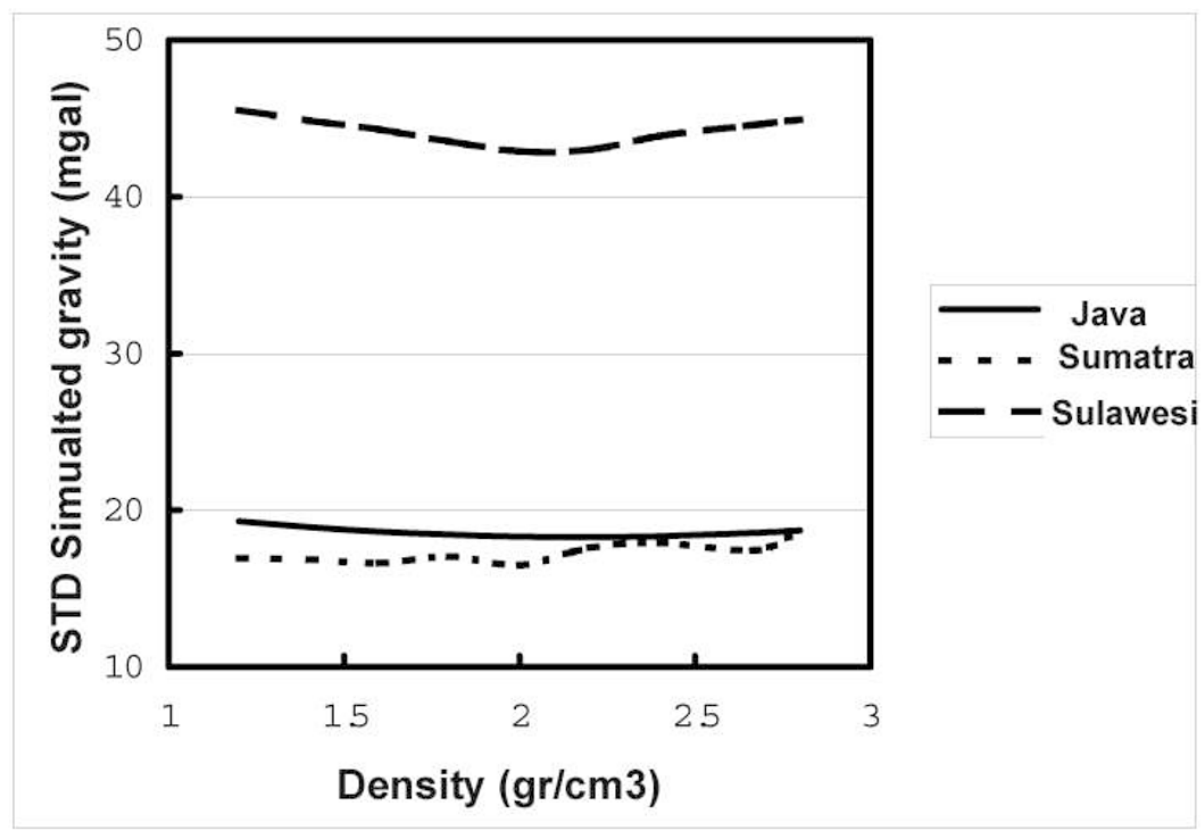

Fig. 6. Relationship between density and simulated gravity.

Table 5. Statistics of differences between EGM96 and observed gravity data, unit in mgal.

\begin{tabular}{lrccrr}
\hline Island & No. data & Minimum & Maximum & Mean & STD \\
\hline Java & 19095 & -109.94 & 252.95 & 1.76 & 24.95 \\
Sumatra & 54335 & -147.16 & 129.75 & -6.50 & 18.10 \\
Sulawesi & 581 & -47.43 & 267.54 & -1.78 & 44.83 \\
\hline
\end{tabular}

tion could be, in this method, the mean value contained also the indirect effect due to an inclusion of the masses within Bouguer plate on the computation.

\subsection{Simulation of the Indonesian land gravity data}

Several parameters influence the results of the RTM computation, including the chosen reference field and the selected density. For this purpose, several reference fields and density values were applied on the computation of gravity effect of topography using the RTM method. Further, the results were compared with the observed gravity data, in which the lowest STD differences show the optimal utilized parameters. The reference parameter was obtained by simply averaging the $30^{\prime \prime} \times 30^{\prime \prime}$ GTOPO30 in several levels from $1^{\prime} \times 1^{\prime}$ to $1^{\circ} \times 1^{\circ}$ with intervals of $30^{\prime \prime}$ using the tcgrid program from GRAVSOFT packages. The area with no elevation were given value 9999. Figure 5 shows the influence of the utilized reference field to the simulated gravity. As can be seen over Java island as well as Sulawesi island, the lowest STD was obtained from the reference field of $25^{\prime}$, while for Sumatra island it is around a reference of $27.5^{\prime}$. Thus, these suggest that the resolution of the suitable reference field over the Indonesia islands is from $25^{\prime}$ to $27.5^{\prime}$.

In addition, several densities were employed on the computation, start from $1.2 \mathrm{gr} / \mathrm{cm}^{3}$ to $2.8 \mathrm{gr} / \mathrm{cm}^{3}$. Figure 6 shows the correlation of the density with STD of the simulated gravity results. It shows that most suitable density was between 2.0 and $2.2 \mathrm{gr} / \mathrm{cm}^{3}$, since this range had lower STD differences. Compared to the others, Java Island gave best com- parison with higher density than the other islands. The reason for this could be that most of the area is volcanic, which usually has higher density.

Based on the above results, we computed the simulated gravity data using RTM method and employing the optimal parameters. The comparisons with the observed gravity data are shown in Table 4. From this table we can see that STD difference ranges from 17 to $42 \mathrm{mgal}$, where the application of optimal parameters decreases the STD differences by about 2 to 3 mgal (compared with Table 3). The STD obtained over Java and Sumatra islands are almost the same. The smallest STD over Sumatra is probably due to the large number of the compared points, as well as to the fact that most of the points are located in relatively lower topograpic areas than those on the other islands, as mentioned above. Compared this STD with the STD differences between EGM96 and observed gravity, in Table 5, there is evident substantial decreasing of STD differences by 2.5 to 7 mgal. A tangible STD decrease again occurs over Java Island, especially over high topographic areas, which is because of additional information obtained from the GTOPO30 data. Moreover, the simulated gravity also show more detailed gravity features than EGM96.

Additionally, the simulated gravity obtained from RTM method was combined with the observed gravity data and gridded together, with the result called combined gravity. It is expected that the observed data values will constrain the simulated data values, thus yielding more reasonable sim- 
(a)
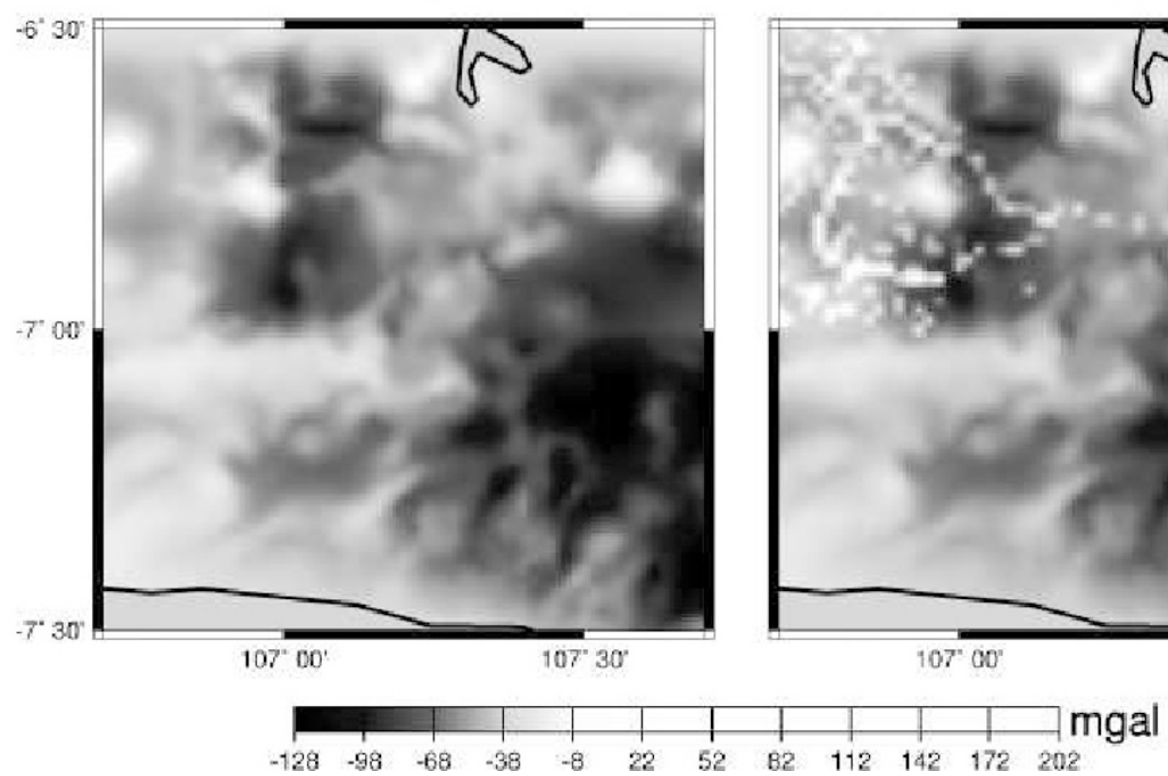

Fig. 7. Comparison of simulated gravity (a) and combined gravity (b).

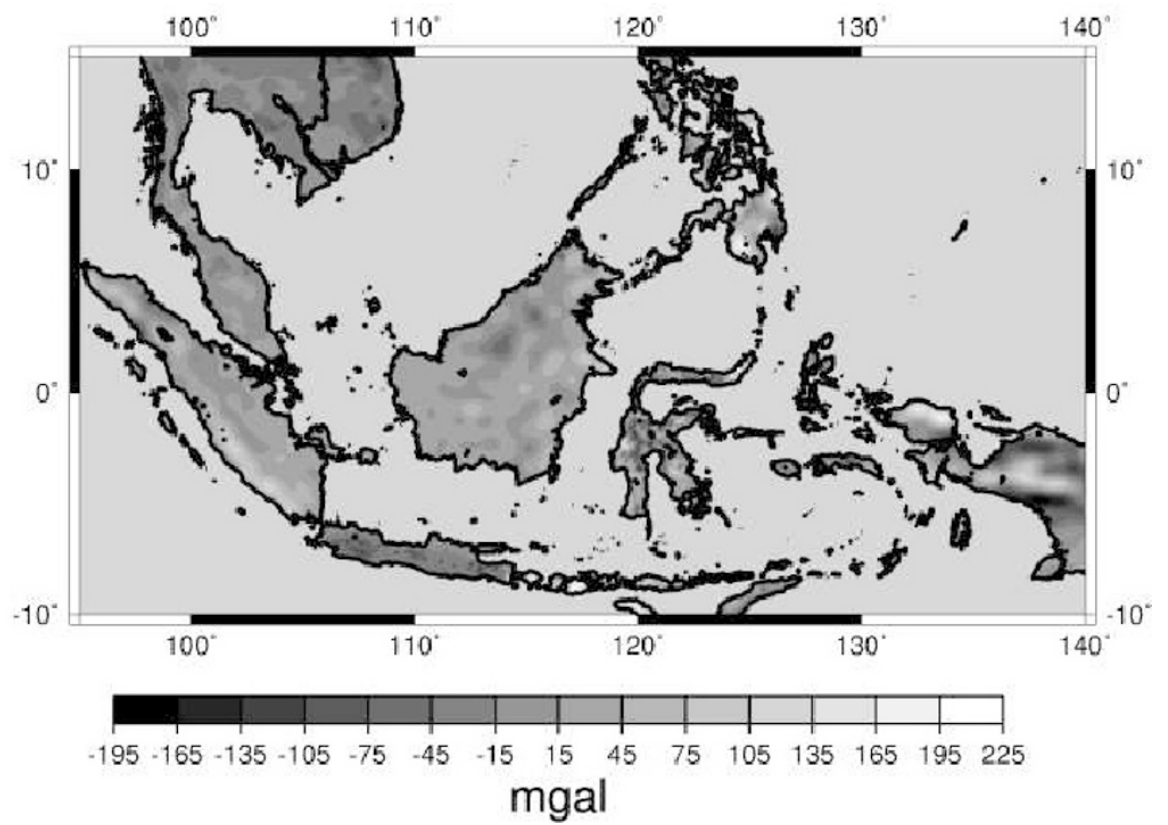

Fig. 8. Indonesian simulated land gravity map. (b)

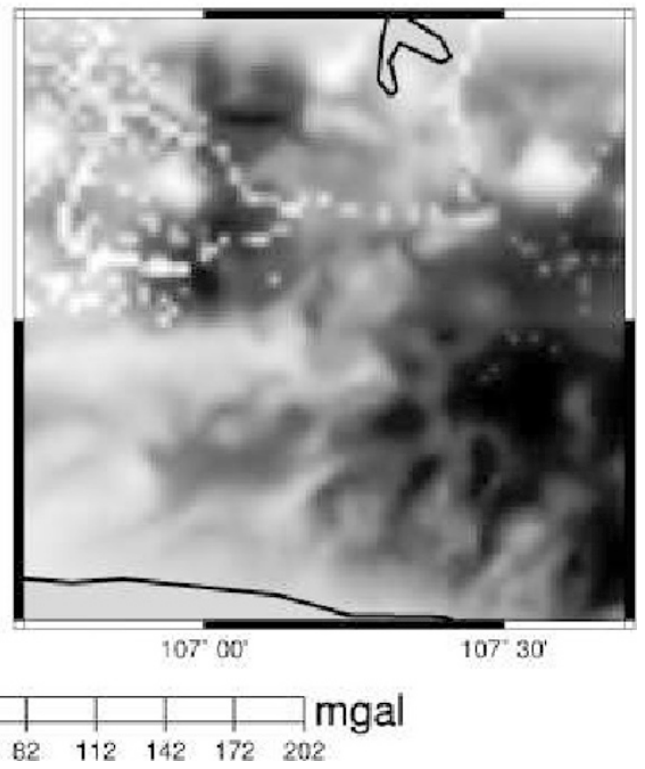

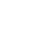

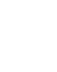


Table 6. Statistics of differences between combined and observed gravity data (at comparison points), unit in mgal.

\begin{tabular}{lcrrrr}
\hline Island & Comparison & Minimum & Maximum & Mean & STD \\
\hline Java & 10.000 & -69.27 & 90.32 & 1.27 & 11.27 \\
Sumatra & 10.000 & -81.42 & 114.11 & -1.18 & 12.31 \\
\hline
\end{tabular}

application, since it is unrestricted by observed gravity and uniformity.

\section{Conclusions}

Using simulation techniques based on a combination of long-wavelength information from EGM96 and gravity effect of topography from GTOPO30 by means of RTM and combination methods, it was shown that unavailability of land gravity data over Indonesian island can be solved in part.

The accuracy of the topographic data, in this case GTOPO30, is needed, since the short-wavelength part of the local gravity is expected to be solved by the information contained in it. Over the Indonesian islands, GTOPO30 is mostly lower than the observed data, especially over high topography areas.

The simulation process using RTM method is influenced by the chosen reference field and density. Over the Indonesia area, the optimal reference field tends to be between $25^{\prime}$ and $27.5^{\prime}$, and optimal density ranges from 2.0 to $2.2 \mathrm{gr} / \mathrm{cm}^{3}$. The STD differences between the simulation results with the observed gravity data were estimated to be around 17-42 mgal. Compared to the STD differences between EGM96 and observed gravity, it was decreased by 2.5-7 mgal. Moreover, it also models more detailed gravity features.

In addition, the combined gravity has also been derived from a combination of simulated gravity and observed gravity. As this data set already contains the observed gravity data, the combined gravity captures more reliable and detailed gravity features compared to the simulated-only gravity. This study should lead to a better understanding for deriving simulated land gravity data and solving unavailability of land gravity data.

Acknowledgments. We gratefully acknowledge GRDC (Geology Research and Development Center of Indonesia) and BAKOSURTANAL (National Coordination Agency for Survey and Mapping of Indonesia) for supplying observed gravity and height data. Thank also to Dr. R. Forsberg and anonymous reviewers for their constructive comments.

\section{References}

Bajracharya, S., C. Kotsakis, M. G. Sideris, Geoid Determination Using Different Gravity Reduction Techniques, Presented in IAG meeting, Budapest, 2001.

Featherstone, W. E., J. F. Kirby, A. H. W. Kearsley, J. R. Gilliland, G. M. Johnston, J. Steed, R. Forsberg, and M. G. Sideris, The AUSGeoid98 geoid model of Australia: data treatment, computations and comparisons with GPS-levelling data, J. Geod., 75-5/6, 313-330, 2001.

Forsberg, R., Gravity field terrain effect computation by FFT, Bull. Geod., 59, 342-360, 1985.

Getech, South East Asia gravity project, Technical report, Getech, 1995.

Heiskanen, W. H. and H. Moritz, Physical Geodesy, Freeman, San Francisco, 1967.

Kahar, J., A. Kasenda, and K. Prijatna, The Indonesian Geoid model 1996, in Gravity, geoid and marine geodesy, edited by J. Segawa, H. Fujimori, and S. Okubo, International Association of Geodesy Symposia, 117, pp. 613-620, Springer, Berlin Heidelberg New york, 1997.

Kearsley, A. H. W. and Z. Ahmad, Problems with geoid evaluation in South East Asia, in Gravity and Geoid, edited by H. Sunkel and I. Marson, International Association of Godesy Symposia,113, pp. 433-438, Springer, Berlin Heidelberg New york, 1994.

Lemoine, F. G., D. E. Smith, L. Kunz, R. Smith, E. C. Palvis, N. K. Palvis, S M. Klosko, D. S. Chinn, M. H. Torrence, R. G. Williamson, C. M. Cox, K. E. Rachlin, Y. M. Wang, S. C. Kenyon, R. Salman, R. G. Trimmer, R. H. Rapp, S. Nerem, The development of the joint NASA GSFC and DMA joint geopotential model, in Gravity, Geoid and Marine Geodesy, edited by J. Segawa, H. Fujimori, S. Okubo, International Association of Geodesy Symposia, 117, pp. 461-469, Springer, Berlin Heidelberg New york, 1997.

Omang, O. C. D. and R. Forsberg, How to handle topography in practical geoid determination: three examples, J. Geod., 74-6; 458-466, 2000.

Prijatna, K., A strategy for geoid determination in the Indonesian archipelago, DEOS Progress Letters, 1, 101-122, 1998.

Tscherning, C. C., R. Forsberg, and P. Knudsen, The GRAVSOFT package for geoid determination, Proc 1st IAG Continental Workshop of the Geoid in Europe, edited by P. Holota and M. Vermeer, 327-334, Prague, 1992.

U.S Geological Survey, The GTOPO30 Documentation, Land Processing Distributed Active Center on the WWW (URL:http://edcdaac.usgs.gov/ gtopo30/gtopo30.html), 1996.

Wessel, P. and W. H. F. Smith, Free Software helps maps and display data, EOS Trans Am Geophys Union, 72: 441, 445-446, 1991.

L. S. Heliani (e-mail: leni@kugi.kyoto-u.ac.jp), Y. Fukuda, and S. Takemoto 